\title{
Clinical and Epidemiological Characteristics of Kawasaki Disease
}

\author{
Ahmad Shamsizadeh ${ }^{1,2,}$; Tahereh Ziaei Kajbaf $^{2}$; Maryam Razavi $^{2}$; Bahman Cheraghian ${ }^{3}$ \\ ${ }_{1}^{1}$ Infectious and Tropical Diseases Research Center, Health Research Institute, Ahvaz Jundishapur University of Medical Sciences, Ahvaz, IR Iran \\ ${ }^{2}$ Aboozar Children's Hospital, Ahvaz Jundishapur University of Medical Sciences, Ahvaz, IR Iran \\ ${ }^{3}$ Aboozar Children's Hospital, Ahvaz Jundishapur University of Medical Sciences, Ah
${ }^{S}$ School of Health, Ahvaz Jundishapur University of Medical Sciences, Ahvaz, IR Iran \\ ${ }^{*}$ Corresponding author:Ahmad Shamsizadeh, Infectious and Tropical Diseases Research Center, Ahvaz Jundishapur University of Medical Sciences, Ahvaz, IR Iran. Tel: +98-9161136128, \\ Fax:+98-6114433715, E-mail: shamsizadeh@ajums.ac.ir \\ Received: March 2, 2013; Revised: July 23, 2013; Accepted: May 17, 2014
}

\begin{abstract}
Background: Kawasaki disease (KD) is an acute multisystem vascular syndrome of unknown etiology that is the leading cause of acquired heart disease in children of developed counties.

Objectives: We aimed to evaluate the epidemiological characteristics and clinical manifestations of KD in children residing in the southwest of Iran.

Patients and Methods: In this retrospective study, we reviewed the medical records of all children with KD who had been admitted to the main children's hospital of Ahvaz, southwest Iran, from March 2000 to March 2010. Data regarding clinical and epidemiological characteristics, management, and the outcome of disease for each patient were obtained. The patients were divided into cardiac and noncardiac groups based on echocardiographic results.

Results: In total, 104 patients with KD (66 boys and 38 girls) were enrolled in this study. The male to female ratio was 1.7:1. The mean \pm SD age of the patients was $33.6 \pm 24.2$ months. Most $(87.2 \%)$ cases were from urban areas. The disease occurred more frequently during winter and spring. Furthermore, $61.5 \%$ of the children had the criteria of classic KD, and $38.5 \%$ were labeled as incomplete KD. The mean \pm SD of the duration of hospital stay was $6.9 \pm 2.4$ days. The mean time between illness and admission to the hospital was $6.47 \pm 2.6$ days. The most common sign was fever, followed by conjunctivitis and oral changes. In total, $20 \%$ of the patients had cardiac abnormalities. There was no significant statistical difference between the cardiac and non-cardiac groups according to age, sex, clinical manifestations, laboratory findings, and cessation of fever. The duration of hospital stay and the time between onset of illness and diagnosis were longer in the cardiac group. All patients received intravenous immunoglobulin and aspirin. Only one patient continued to have cardiac abnormalities after 6 months of follow-up.

Conclusions: Kawasaki disease is not rare in southwest of Iran. The age, gender distribution and clinical findings are similar to that of other reports. Patients with cardiac abnormalities had delayed treatment and prolonged hospital stays.
\end{abstract}

Keywords: Kawasaki Disease; Epidemiology; Iran; Mucocutaneous Lymph Node Syndrome

\section{Background}

Kawasaki disease (KD), formerly known as mucocutaneus lymph node syndrome, is an acute multisystem vasculitis of small and medium sized vessels that occurs prominently in children younger than five years of age (1). This disease was first described by Dr. Tamisaku Kawasaki in 1967 (2). He saw his first case of an unusual illness in a four-year-old child with a rash and fever at the Red Cross Hospital of Tokyo, Japan, during January of 1961 (3). Following the initial reports of the disease, it became apparent that this illness was not benign, since a number of children were reported to die of this illness, usually as a result of cardiovascular complications (4).

The etiology of KD is still unknown and no single pathognomonic clinical or laboratory findings for its definitive diagnosis have been identified (5). The diagnosis of classic KD is based on clinical criteria which include fever for at least five days and four or more of the following five features: 1) bilateral conjunctival injection; 2) cervical lymphadenopathy; 3) oral mucosal changes; 4) polymorphous rashes; 5) swelling or redness of the extremities, and the exclusion of alternative diagnoses (6). Fever is typically hectic and remittent, with peak temperatures frequently exceeding $39^{\circ} \mathrm{C}$ or higher. The fever is unresponsive to antibiotics but partially responds to antipyretics. For untreated children, the febrile period lasts for a mean of 11 days (1). Bilateral painless vascular injection of the bulbar conjunctivae is generally seen in the first week of illness. Patients sometimes have follicular palpebral conjunctivitis.

Conjunctival injection is not associated with exudate, edema or corneal ulceration. Cervical lymphadenopathy is usually unilateral and confined to the anterior cervical triangle. The enlarged node or mass of nodes is usually more than $1.5 \mathrm{~cm}$, is non-fluctuant, may or may not be associated with erythema of the overlying skin and is only moderately tender (1). Changes in the mouth and lips are characterized by erythema, dryness, fissuring, cracking and bleeding of the lips, diffuse erythema

Copyright (C 2014,Ahvaz Jundishapur University of Medical Sciences; Published by Kowsar Corp. This is an open-access article distributed under the terms of the Creative Commons Attribution License, which permits unrestricted use, distribution, and reproduction in any medium, provided the original work is properly cited. 
of the oral and pharyngeal mucosa, strawberry tongue with erythema and prominent papillae. Oral ulceration, exudates, and Koplik's spots rarely, if ever, are found in KD (7). Rashes in KD tend to be most prominent on the trunk but frequently also involve the face and extremities (1). Rashes in KD may take any of the several forms. The most common is a macular-popular, primarily truncal erythematous rash. A scarlatiniform rash and an erythema multiforme-like rash with target lesions are also seen. Prineal rashes have been emphasized by many observers (1).

Changes in the extremities are among the most distinctive features of KD. During its initial stage, the palms and soles are diffusely and deeply erythematous with induration and swelling. In the convalescent stage, membranous desquamation from the fingertips may occur (8). The other associated features of KD include: extreme irritability that is especially prominent in infants, sterile pyuria, mild hepatitis, obstructive jaundice, arthralgia and arthritis, aseptic meningitis, diarrhea, myocardiopathy, pericardial effusion, myocardial infarction and hydrops of the gallbladder (1). Erythema, induration or crust at the BCG inoculation site are listed as significant findings among the diagnostic guidelines for KD by the American Heart Association (5).

Children presenting less symptoms than the four classical features of KD are said to have "incomplete or atypical KD" (9). Incomplete KD is more common in young infants than in older children, and leads to inaccurate diagnosis and timely treatment, which is especially important for young patients who are at a substantial risk of developing coronary abnormalities. The concept of "incomplete KD" has emerged in the recent years. Many experienced clinicians have encountered patients with an inflammatory disorder who did not meet the clinical case definition, but in whom an echocardiogram documented coronary artery abnormalities, thus confirming the diagnosis of $\mathrm{KD}$ as a systemic vasculitic syndrome having heterogeneous features rather than a single clinical entity $(3,10)$.

There is no specific diagnostic test for KD, but there are certain laboratory findings are characteristics. This disease is characterized by leukocytosis, especially granulocytosis with high band form counts, and elevated platelet in the second and third weeks of the illness. Anemia may develop, usually with normal red blood cell indexes. Elevated erythrocyte sedimentation rate (ESR), C-reactive protein (CRP), and other acute phase reactants are present in the acute phase of the disease. Moderate elevation in serum transaminases and hypoalbuminemia occur in these patients (1). Administration of high dose intravenous immunoglobulin (IVIG) in combination with aspirin treatment, within the first 10 days after the onset of fever, has been shown to reduce the rate of major complications (coronary artery abnormalities) from $20-25 \%$ to $3-5 \%(4,9,11,12)$.

Kawasaki disease is diagnosed after exclusion of other diseases, and the differentiation between KD and similar diseases is sometimes difficult. Better recognition of various presentations of KD helps prevent misdiagnosis and over-diagnosis of this disease. Considering that 20\% of patients with KD develop coronary artery abnormalities and some of these patients do not fulfill the classic criteria for $\mathrm{KD}$, better recognition of presenting signs and symptoms of KD is important for early diagnosis of the disease and prevention of complications. To the best of our knowledge, the first report on KD in Iranian children in the English literature was published in 2001 (13) and since, there has been no comprehensive studies on patients with KD in southwest Iran, the authors conducted a retrospective study of the epidemiological characteristics, clinical manifestations, and laboratory findings of KD in Ahvaz, southwest Iran.

\section{Objectives}

The objective of this study was to determine the most common clinical and epidemiological features of KD in order to improve early diagnosis of this disease and prevent its complications.

\section{Patients and Methods}

In this retrospective study, we reviewed the medical records of all children with KD who had been admitted to Aboozar Children's Hospital (the main pediatric hospital of Ahvaz, southwestern Iran) from March 2000 to March 2010. All patients who met the criteria for KD, according to the American Heart Association and American Academy of Pediatrics guidelines, were included in the study $(6,14)$. Information concerning epidemiological characteristics, clinical manifestations, laboratory and echocardiographic findings, disease management and outcome for each case was obtained. Echocardiography was performed upon diagnosis, and one week, three weeks, three months, and six months after diagnosis. Data were analyzed using the SPSS software version 15.00. Results are presented as mean \pm standard deviation for quantitative variables and percentages (\%) for qualitative. Chi-square and t test were used as appropriate. A P value less than 0.05 were considered significant.

\section{Results}

In total, 104 patients were enrolled in our study. Amongst these cases, 66 (63.5\%) were boys and 38 (36.5\%) girls (male to female ratio $=1.7: 1$ ). The age of the patients ranged from 3 months to 8 years (mean \pm SD $=33.6 \pm$ 24.2 months). Figure 1 shows the age distribution of the patients with KD. Furthermore, 86 (82.7\%) patients were from urban and 18 (17.3\%) patients from rural areas. More patients were seen during winter (41.3\%) and spring (11.5\%), but this difference was not significant $(\mathrm{P}=$ 0.33 ). Most patients were referred to the hospital during February and April (Figure 2). 
Shamsizadeh A et al.

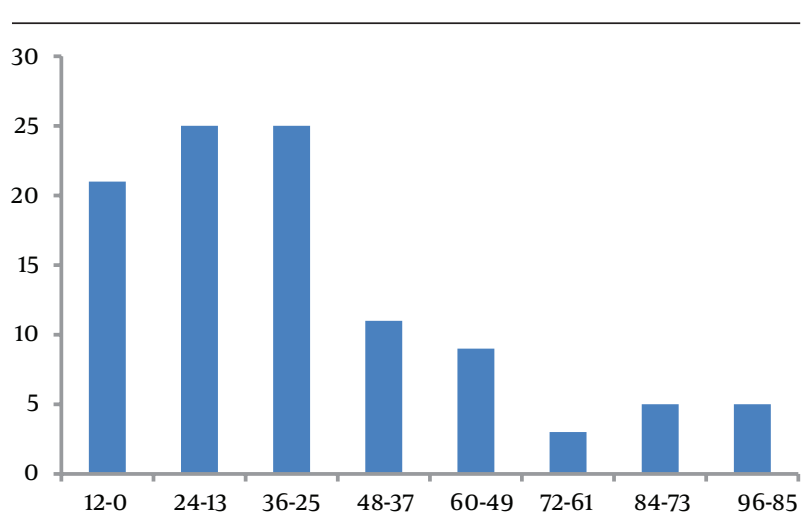

Figure 1. Age Distribution of the Patients With Kawasaki Disease by Month

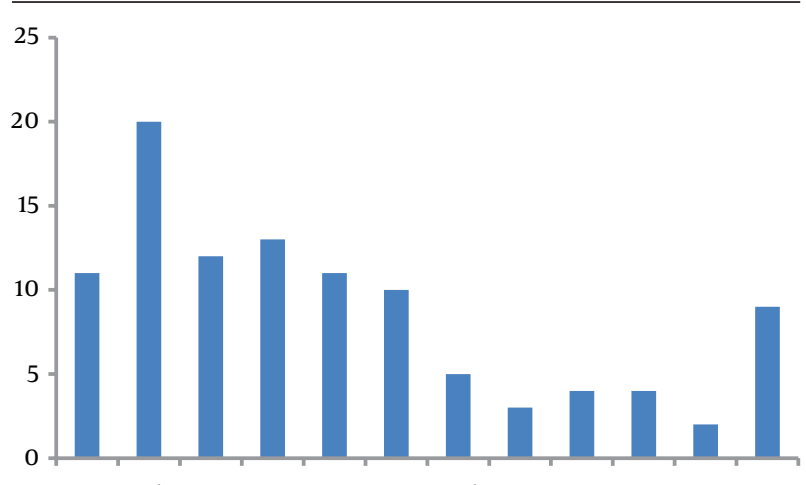

Jan Feb Mar Apr May Jun Jul Aug Sep Oct Nov Dec

Figure 2. Yearly Distribution of the Patients With Kawasaki Disease

Table 1. Clinical Manifestations of Children With Kawasaki Disease $(\mathrm{n}=104)^{\mathrm{a}}$

\begin{tabular}{lc}
\hline Signs and Symptoms & Results \\
\hline Fever & $104(100)$ \\
\hline Conjunctivitis & $93(89.4)$ \\
\hline Oral changes & $90(86.5)^{\mathrm{b}}$ \\
\hline Skin rashes & $79(76)$ \\
\hline Extremities changes & $69(66.3)^{\mathrm{b}}$ \\
\hline Cervical lymphadenopathy & $44(42.3)$ \\
\hline Anorexia & $36(36.4)$ \\
\hline Prineal erythema & $33(31.7)$ \\
\hline Coryza & $31(29.8)^{\mathrm{b}}$ \\
\hline Irritability & $27(26)$ \\
\hline Vomiting & $24(23.1)$ \\
\hline Diarrhea & $18(17.3)$ \\
\hline Arthralgia & $15(14.4)$ \\
\hline Cough & $13(12.5)$ \\
\hline Hepatomegaly & $7(6.7)^{\mathrm{b}}$ \\
\hline
\end{tabular}

\footnotetext{
a Data are No. (\%).

$\mathrm{b}$ The total number is 104 .
}

Overall, 64 (61.5\%) children fulfilled the diagnostic criteria for classic KD and 40 (38.5\%) were diagnosed with incomplete $\mathrm{KD}$. The mean \pm SD of hospital stay duration was $6.9 \pm 2.4$ days. The mean \pm SD time between the onset of illness and diagnosis was $6.47 \pm 2.6$ days. The mean \pm SD temperature of patients was $38.65 \pm 0.87^{\circ} \mathrm{C}$. The most common sign was fever, followed by conjunctivitis and oral mucosal changes. Table 1 shows the clinical manifestations of patients with KD.

Laboratory findings of the children are summarized in Table 2. Most patients had high ESR and WBC with predominance of neutrophils. All patients were divided into two groups according to their echocardiographic results; patients with echocardiographic abnormalities (cardiac group) and patients with normal echocardiographic results (non-cardiac group). Twenty-one (20\%) patients belonged to the cardiac group; 13 (61.9\%) of them were boys and 8 (38.1\%) girls. Cardiac abnormalities consisted of mild ectasia of the left and right coronary arteries (12 patients), ectasia of the left main coronary artery and left anterior descending artery (three patients), giant aneurysm of the left coronary artery (one patient), mild mitral regurgitation (two patients), and tricuspid insufficiency (three patients). There was no significant statistical difference between the cardiac and non-cardiac groups regarding age, sex, clinical manifestations, laboratory findings and cessation of fever. The duration of hospital admission was significant for the cardiac group $(\mathrm{P}=0.004)$. The time between onset of illness and diagnosis was longer for the cardiac group $(\mathrm{P}=0.016)$. Table 3 shows some characteristics of KD in both groups.

All patients were treated with a single dose of $2 \mathrm{~g} / \mathrm{kg}$ IVIG and aspirin (80-100 mg/kg/day) in four divided doses. Aspirin was decreased to $3-5 \mathrm{mg} / \mathrm{kg} /$ day after two weeks and continued for two months. Most patients responded well to the initial therapy. The mean \pm SD time of cessation of fever after treatment was $1.34 \pm 1.13$ day. One patient needed three doses of IVIG and methyl prednisolone for three days. One Patient firstly presented fever and jaundice, while signs and symptoms of KD appeared later. Eventually, in serial echocardiography follow-up, cardiac abnormalities recovered in 103 patients. In one patient giant aneurysm persisted after six months and he was put on long-term anticoagulant therapy.

Table 2. Laboratory Findings of Children With Kawasaki Disease $(\mathrm{n}=104)^{\mathrm{a}, \mathrm{b}}$

\begin{tabular}{|c|c|c|}
\hline Test & Number & Results \\
\hline $\mathrm{WBC} / \mathrm{mm}^{3}$ & 104 & $15474 \pm 3965$ \\
\hline PMN, \% & 98 & $67.9 \pm 14.4$ \\
\hline Hemoglobulin, g/dL & 103 & $10.5 \pm 1.4$ \\
\hline Platelet count $/ \mathrm{mm}^{3}$ & 102 & $457137 \pm 242598$ \\
\hline ESR, $\mathbf{m m} / \mathbf{1}^{\text {st }} \mathbf{h}$ & 102 & $82.2 \pm 31$ \\
\hline Aspartate aminotransferase, IU/L & 33 & $53.27 \pm 41.85$ \\
\hline Alanine aminotransferase, IU/L & 33 & $74.88 \pm 48.24$ \\
\hline Alkaline phosphate, IU/L & 32 & $473 \pm 295.29$ \\
\hline
\end{tabular}

a Abbreviations: WBC, white blood cells; PMN, polymorphonuclear; ESR, erythrocyte sedimentation rate.

b Data are presented as Mean \pm SD 
Shamsizadeh A et al.

\begin{tabular}{|c|c|c|c|}
\hline Variable & Cardiac Group & Non Cardiac Group & P Value \\
\hline \multicolumn{4}{|l|}{ Gender } \\
\hline Male & 1.8 & 1.6 & \\
\hline Female & 1 & 1 & \\
\hline Age, months & $31.29 \pm 23.31$ & $34.18 \pm 24.52$ & NS \\
\hline $\begin{array}{l}\text { Duration of fever before } \\
\text { treatment, } d\end{array}$ & $7.71 \pm 2.79$ & $6.16 \pm 2.56$ & 0.016 \\
\hline Hospital duration, $d$ & $8.38 \pm 2.59$ & $6.63 \pm 2.35$ & 0.004 \\
\hline Cessation of fever, $d$ & $1.48 \pm 0.98$ & $1.30 \pm 1.17$ & NS \\
\hline Temperature, & $38.81 \pm 0.74$ & $38.60 \pm 0.90$ & NS \\
\hline $\mathrm{WBC} / \mathrm{mm}^{3}$ & $15604 \pm 7925$ & $15440 \pm 5419$ & NS \\
\hline PMN, \% & $63 \pm 16$ & $68 \pm 13$ & NS \\
\hline Lymphocytes, \% & $35 \pm 16$ & $30 \pm 13$ & NS \\
\hline Hemoglobulin, $\mathrm{g} / \mathrm{dL}$ & $9.55 \pm 1.36$ & $10.17 \pm 1.39$ & NS \\
\hline Platelet count $/ \mathrm{mm}^{3}$ & $480000 \pm 287012$ & $449481 \pm 231129$ & NS \\
\hline ESR, mm/1st h & $83 \pm 32$ & $81 \pm 30$ & NS \\
\hline
\end{tabular}

a Abbreviations: ESR, erythrocyte sedimentation rate; NS, not significant; PMN, polymorphonuclear; WBC, white blood cells.

$\mathrm{b}$ Data are presented as Mean \pm SD.

\section{Discussion}

We reported the epidemiological characteristics, clinical manifestations, management, and disease outcome for children with KD in southwest Iran. The mean age at the onset of the disease (33 months) was similar to the mean age reported from Iran (15) Jamaica (16) china (17) and Korea (18). The male preponderance in this study was similar to most studies, (19-23), yet lower than studies from China and Sweden $(24,25)$. In our study, similar to a study from the United States of America, the disease was more common in winter and spring (26) yet, in other studies, KD had a peak incidence during other seasons (4, 27). In one study from Iran, there was no clear-cut seasonal difference in the incidence of $\mathrm{KD}(28)$.

The clinical manifestations of KD in our study were similar to other studies. Oral changes and conjunctivitis were the most common cardinal features $(4,22,28-30)$ while lymphadenopathy was the least common cardinal $\operatorname{sign}(15,17,31)$. The high rate of white blood cells (WBC), polymorphonuclear (PMN) leukocytes, platelet count and ESR was similar to other reports $(1,13,18,27,30,31)$. This study was a retrospective study and had the limitations of this type of studies. Some information was not recorded correctly and accurately and some medical records had missing data.

Some laboratory results were not recorded for all children. In regards to the considerable number of patients with incomplete KD, for each young child with prolonged and unexplainable fever, KD should be considered during the differential diagnosis. In this study, 21 (20\%) patients had cardiac abnormalities. The frequency of cardiac ab-

normalities are different in reports from Thailand (6.2\%) (32), Taiwan (11\%), (33) Hong Kong (15\%) (22), USA (17\%) (34), Oman (25\%) (4), Finland (28\%) (35), China (32\%) (24), and Turkey (33\%) (30). There was no significant difference between the cardiac and non-cardiac patients except for the duration of hospital course and interval between onset of disease and treatment. Similar to some studies, in patients with cardiac abnormalities, the treatment begun later and the hospital course was longer (17). In one study from Pakistan, delayed treatment and fever more than 10 days at the time of initial presentation were risk factors for development of cardiac abnormalities (36).

In this study, the response of patients to IVIG and aspirin was good and fever subsided shortly after IVIG administration. Cardiac abnormalities resolved in all patients except one. One limitation of our study was the relatively short follow-up period (6 months). Kawasaki disease is a relatively common disease in the southwest of Iran. The disease is more prevalent in males and young children and occurs mostly during winter and spring. A considerable portion of patients, do not fulfill the criteria of classic KD (incomplete KD). The rate of cardiac abnormality is $20 \%$ and patients respond well to administration of IVIG and aspirin. Prolonged fever and delayed treatment were risk factors for developing cardiac abnormalities.

\section{Acknowledgements}

We thank Mrs. Shohreh Nabidavoodi for the preparation of this manuscript. 


\section{Authors' Contributions}

Ahmad Shamsizadeh: study concept and design, analysis and interpretation of data and drafting of the manuscript. Tahereh Ziaei Kajbaf and Maryam Razavi: collecting of data. Bahman Cheraghian: statistical analysis.

\section{References}

1. Shulman ST. Kawasaki Disease. In: Feigin RD, Cherry JD, Demmler Harrison GJ, Kaplan SL editors. Feigin \& Cherry's Textbook of Pediatric Infectious Diseases. Philadelphia: Saunders Elsevier; 2009. pp. $1153-75$.

2. Kawasaki T. [Acute febrile mucocutaneous syndrome with lymphoid involvement with specific desquamation of the fingers and toes in children]. Arerugi.1967;16(3):178-222.

3. Kim DS. Kawasaki Disease. Yonsei Med J. 2006;47(6):759-72.

4. Bhatnagar SK, Paul G, Subramanian R, Al Hosni MS, Al Khusaiby SM. Kawasaki disease in Oman-a clinical study. J Trop Pediatr. 2003;49(6):361-6.

5. Seo JH, Yu JJ, Ko HK, Choi HS, Kim YH, Ko JK. Diagnosis of incomplete kawasaki disease in infants based on an inflammation at the bacille calmette-guerin inoculation site. Korean Circ J. 2012;42(12):823-9.

6. Freeman AF, Shulman ST. Kawasaki disease: summary of the American Heart Association guidelines. Am Fam Physician. 2006;74(7):1141-8.

7. Rowley AH, Shulman ST. Kawasaki syndrome. Clin Microbiol Rev. 1998;11(3):405-14.

8. Takahashi K, Oharaseki T, Yokouchi Y, Hiruta N, Naoe S. Kawasaki disease as a systemic vasculitis in childhood. Ann Vasc Dis. 2010;3(3):173-81.

9. Singh S, Kawasaki T. Kawasaki disease - an Indian perspective. Indian Pediatr. 2009;46(7):563-71.

10. Gulhan B, Kesici S, Beken S, Cilsal E, Kale G, Alehan D, et al. Varying clinical features of Turkish Kawasaki disease patients. Turk J Pediatr. 2012;54(1):1-6.

11. Kim SH, Kim KH, Kim DS. Clinical characteristics of Kawasaki disease according to age at diagnosis. Indian Pediatr. 2009;46(7):58590

12. Juan CC, Hwang B, Lee PC, Lin YJ, Chien JC, Lee HY, et al. The clinical manifestations and risk factors of a delayed diagnosis of Kawasaki disease. J Chin Med Assoc. 2007;70(9):374-9.

13. Sadeghi E, Amin R, Ajamee GH. Kawasaki syndrome: the Iranian experience. East Mediterr Health J. 2001;7(1-2):16-25.

14. Newburger JW, Takahashi M, Gerber MA, Gewitz MH, Tani LY, Burns JC, et al. Diagnosis, treatment, and long-term management of Kawasaki disease: a statement for health professionals from the Committee on Rheumatic Fever, Endocarditis and Kawasaki Disease, Council on Cardiovascular Disease in the Young, American Heart Association. Circulation. 2004;110(17):2747-71.

15. Saffar MJ, Reshidighader F. Kawasaki disease in East Mazandaran, Islamic Republic of Iran, 1997-2002. East Mediterr Health J. 2005;11(1-2):28-35.

16. Pierre R, Sue-Ho R, Watson D. Kawasaki syndrome in Jamaica. Pediatr Infect Dis J. 200 0;19(6):539-43.
17. Du ZD, Zhang T, Liang L, Meng X, Li T, Kawasaki T, et al. Epidemiologic picture of Kawasaki disease in Beijing from 1995 through 1999. Pediatr Infect Dis J. 2002;21(2):103-7.

18. Park YW, Han JW, Park IS, Kim CH, Cha SH, Ma JS, et al. Kawasaki disease in Korea, 2003-2005. Pediatr Infect Dis J. 2007;26(9):821-3.

19. Royle JA, Williams K, Elliott E, Sholler G, Nolan T, Allen R, et al. Kawasaki disease in Australia, 1993-95. Arch Dis Child.1998;78(1):33-9.

20. Lee KY, Han JW, Lee HS, Hong JH, Hahn SH, Lee JS, et al. Epidemiologic study of Kawasaki disease at a single hospital in Daejeon, Korea (1987 through 2000). Pediatr Infect Dis J. 2004;23(1):52-5.

21. Chang LY, Chang IS, Lu CY, Chiang BL, Lee CY, Chen PJ, et al. Epidemiologic features of Kawasaki disease in Taiwan, 1996-2002. Pediatrics. 2004;114(6):e678-82.

22. Ng YM, Sung RY, So LY, Fong NC, Ho MH, Cheng YW, et al. Kawasaki disease in Hong Kong, 1994 to 2000. Hong Kong Med J. 2005;11(5):331-5.

23. Huang GY, Ma XJ, Huang M, Chen SB, Huang MR, Gui YH, et al. Epidemiologic pictures of Kawasaki disease in Shanghai from 1998 through 2002. J Epidemiol. 2006;16(1):9-14.

24. Lee BW, Tay JS, Yip WC, Yap HK, Chan KY, Low PS. Kawasaki syndrome in Chinese children. Ann Trop Paediatr.1989;9(3):147-51.

25. Schiller B, Fasth A, Bjorkhem G, Elinder G. Kawasaki disease in Sweden: incidence and clinical features. Acta Paediatr. 1995;84(7):769-74.

26. Chang RK. Hospitalizations for Kawasaki disease among children in the United States, 1988-1997. Pediatrics. 2002;109(6).

27. Huang WC, Huang LM, Chang IS, Chang LY, Chiang BL, Chen PJ, et al. Epidemiologic features of Kawasaki disease in Taiwan, 20032006. Pediatrics. 2009;123(3):e401-5.

28. Asadi-Pooya AA, Borzoee M, Amoozgar H. The experience with 113 patients with Kawasaki disease in Fars Province, Iran. Turk J Pediatr. 2006;48(2):109-14.

29. Suresh N, Varadarajan VV, Ranjith MS. Kawasaki disease in south India: a prospective, case-control study. Ann Trop Paediatr. 2007;27(4):277-83.

30. Ozdemir H, Ciftci E, Tapisiz A, Ince E, Tutar E, Atalay S, et al. Clinical and epidemiological characteristics of children with Kawasaki disease in Turkey. J Trop Pediatr. 2010;56(4):260-2.

31. Singh S, Bansal A, Gupta A, Kumar RM, Mittal BR. Kawasaki disease: a decade of experience from North India. Int Heart J. 2005;46(4):679-89.

32. Chaiyarak K, Durongpisitkul K, Atta T, Soongswang J, Laohaprasitiporn D, Nana A. Clinical manifestations of Kawasaki disease: what are the significant parameters? Asian Pac J Allergy Immunol. 2009;27(2-3):131-6.

33. Liu HC, Lo CW, Hwang B, Lee PC. Clinical manifestations vary with different age spectrums in infants with Kawasaki disease. Sci World J. 2012;2012:210382.

34. Marquez J, Gedalia O, Candia L, Ranjit K, Hescock GC, Espinoza LR, et al. Kawasaki disease: clinical spectrum of 88 patients in a high-prevalence African-American population. J Natl Med Assoc. 2008;100(1):28-32.

35. Salo E. Kawasaki disease in Finland in 1982-1992. Scand J Infect Dis. 1993;25(4):497-502.

36. Akhtar S, Alam MM, Ahmed MA. Cardiac involvement in Kawasaki disease in Pakistani children. Ann Pediatr Cardiol. 2012;5(2):12932. 